\title{
Ttn as a likely causal gene for QTL of alcohol preference on mouse chromosome 2
}

\author{
Lishi Wang ${ }^{1,2}$, Yan Jiao ${ }^{1}$, Yue Huang ${ }^{1}$, Beth Bennett ${ }^{3}$, Robert W Williams ${ }^{4}$, Dawei Li ${ }^{5}$, Hongyu Zhao ${ }^{6,7}$, \\ Joel Gelernter ${ }^{5,7,8,9}$, Henry R Kranzler ${ }^{10,11}$, Lindsay A Farrer ${ }^{12}$, Weikuan Gu ${ }^{1 *}$ \\ From UT-KBRIN Bioinformatics Summit 2014 \\ Cadiz, KY, USA. 11-13 April 2014
}

\section{Background}

Many quantitative trait loci (QTL) influencing mouse model phenotypes for alcoholism have been mapped genetically. However, the gene(s) comprising the QTL (QTG) are largely unknown. In previous work, Bennett and colleagues created congenic strains carrying the DBA/2IBG (D2) region for alcohol preference (AP) on chromosome 2, on a C57BL/6IBG (B6) background [1]. Subsequently, interval specific congenic recombinant strains (ISCRS), in which the full D2 QTL region was broken into smaller, partially overlapping regions of introgression, were generated and tested. With information from two ISCRS, the QTL has been mapped onto mouse chromosome $2(\mathrm{Chr} 2)$ in a region of $3.4 \mathrm{Mb}$ by using C57BL/6J (B6) x DBA/2J (D2) recombinant inbred (RI) strains as well as by using F2 populations. Several candidate genes, Gad1, Atp5g3, Atf2, Sp 3 and $S p 9$, have been evaluated but none of them has been confirmed for a definitive role in the regulation of the QTL of AP on Chr2 [2,3].

\section{Materials and methods}

We have been searching candidate genes for this QTL intensively by using an integrative approach including: 1) bioinformatics tools to search potential functionally relevant genes of alcohol preference within the QTL region [4]; 2) searching for single nucleotide polymorphisms (SNPs) within the exons of every gene between B6 and D2 in the QTL region; 3) conducting real time PCR to examine the differentially expressed genes between B6 and alcohol preferred interval-specific congenic

\footnotetext{
* Correspondence: wgu@uthsc.edu

'Department of Orthopaedic Surgery \& BME - Campbell Clinic and Pathology, University of Tennessee Health Science Center, Memphis, TN 38163, USA

Full list of author information is available at the end of the article
}

recombinant strains (ISCRS); and 4) analysis of the association of candidate genes in the human population.

\section{Results}

Titin (Ttn) is known as a giant muscle protein expressed in the cardiac and skeletal muscles. However, its expression level in the tongue is known to be higher than that in the heart. We therefore investigated if Ttn plays a role in the regulation of AP. Our data indicated that 1) the expression level of Ttn in the less AP congenic strains is significantly higher than that in $\mathrm{B} 6 ; 2$ ) the expression of a Ttn probe in the BXD RI strains is negatively correlated to that of AP; 3) One SNP is up- and the other is downstream of Ttn. The alcohol consumption of the B6 genotype is significantly higher than that of D2 genotype in the BXD RI strains, based on data from multiple reports using two-bottles of choice; and 4) the polymorphism of TTN in the human population is highly associated with alcoholism.

\section{Conclusions}

We conclude that Ttn is likely a causal gene for the QTL on Ch2 for the AP.

\footnotetext{
Acknowledgements

Research supported by the National Institutes of Health, United States (research grants \#AA016342, \#DA12849, \#DA12690, \#AA017535, \#AA12870, and \#AA11330). Genotyping services were provided by the Center for Inherited Disease Research (CIDR). CIDR is fully funded through a federal contract from the National Institutes of Health to The Johns Hopkins University (contract number N01-HG-65403). Dr. Kranzler has been a paid consultant for Alkermes, Lilly, Lundbeck, Pfizer, and Roche. He also reports associations with Eli Lilly, Janssen, Schering Plough, Lundbeck, Alkermes, GlaxoSmithKline, Abbott, and Johnson \& Johnson, as these companies provide support to the ACNP Alcohol Clinical Trials Initiative (ACTIVE) and Dr. Kranzler has received honoraria from ACTIVE. The other authors report no financial interests or potential conflicts of interest.
} 


\section{Authors' details}

'Department of Orthopaedic Surgery \& BME - Campbell Clinic and Pathology, University of Tennessee Health Science Center, Memphis, TN 38163, USA. ${ }^{2}$ Department of Basic Medical Research, Inner Mongolia Medical University, Hohhot City, Inner Mongolia, 010110, China. ${ }^{3}$ Department of Pharmacology, University of Colorado Denver, Aurora CO 80045-0508, USA. ${ }^{4}$ Department of Anatomy and Neurobiology, University of Tennessee Health Science Center, Memphis, TN, 38163, USA. ${ }^{5}$ Department of Psychiatry, School of Medicine, Yale University, New Haven, CT 06510, USA. ${ }^{6}$ Department of Epidemiology and Public Health, School of Medicine, Yale University, New Haven, CT 06510, USA. ${ }^{7}$ Department of Genetics, School of Medicine, Yale University, New Haven, CT 06510, USA. ${ }^{8}$ VA Connecticut Healthcare Center, West Haven, CT 06516, USA. ${ }^{9}$ Department of Neurobiology, Yale University School of Medicine, New Haven, CT 06510, USA. ${ }^{10}$ Department of Psychiatry, University of Pennsylvania School of Medicine, Philadelphia, PA 19104, USA. ${ }^{11}$ VISN 4 MIRECC, Philadelphia VAMC, Philadelphia, PA 19104, USA.

${ }^{12}$ Departments of Medicine (Biomedical Genetics), Neurology, Ophthalmology, Genetics \& Genomics, Biostatistics, and Epidemiology, Boston University Schools of Medicine and Public Health, Boston, MA 02118, USA.

\section{Published: 29 September 2014}

\section{References}

1. Bennett B, Beeson M, Gordon L, Carosone-Link P, Johnson TE: Genetic dissection of quantitative trait loci specifying sedative/hypnotic sensitivity to ethanol: mapping with interval-specific congenic recombinant lines. Alcohol Clin Exp Res 2002, 26(11):1615-1624.

2. Wang LS, Jiao Y, Huang Y, Liu XY, Gibson G, Bennett B, Hamre KM, Li DW, Zhao HY, Gelernter J, Kranzler HR, Farrer LA, Lu L, Wang YJ, Gu WK: Critical evaluation of transcription factor Atf2 as a candidate modulator of alcohol preference in mouse and human populations. Genet Mol Res 2013, 12(4):5992-6005.

3. Huang Y, Wang L, Bennett B, Williams RW, Wang YJ, Gu WK, Jiao Y: Potential role of Atp5g3 in epigenetic regulation of alcohol preference or obesity from a mouse genomic perspective. Genet Mol Res 2013, 12(3):3662-3674

4. Wang J, Williams RW, Manly KF: WebQTL: Web-based complex trait analysis. Neuroinformatics 2003, 1:299-308.

doi:10.1186/1471-2105-15-S10-P12

Cite this article as: Wang et al.: Ttn as a likely causal gene for QTL of alcohol preference on mouse chromosome 2. BMC Bioinformatics 2014 15(Suppl 10):P12.

\section{Submit your next manuscript to BioMed Central and take full advantage of:}

- Convenient online submission

- Thorough peer review

- No space constraints or color figure charges

- Immediate publication on acceptance

- Inclusion in PubMed, CAS, Scopus and Google Scholar

- Research which is freely available for redistribution 